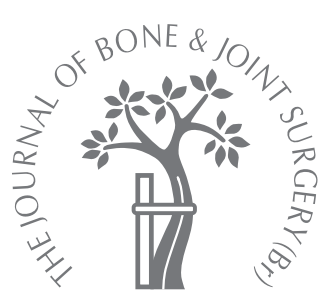

M. J. Oddy,

C. J. Pendegrass,

A. E. Goodship,

S. R. Cannon,

T. W. R. Briggs,

G. W. Blunn

From the Centre for

Biomedical

Engineering, Institute

of Orthopaedics and

Musculo-Skeletal

Science, University

College London, The

Royal National

Orthopaedic Hospital,

Stanmore and the

Royal Veterinary

College, North

Mimms, England

M. J. Oddy, MA, MSc, MRCS,

Research Fellow

C. J. Pendegrass, BSc,

Research Fellow

G. W. Blunn, BSc, PhD,

Professor of Biomedical

Engineering

The Centre for Biomedica

Engineering, Institute of

Orthopaedics and Musculo-

Skeletal Science, University

College London, Brockley Hill,

Stanmore HA7 4LP, UK.

a S. R. Cannon, MA,

MCh(Orth), FRCS. Consultant

Orthopaedic Surgeon

- T. W. R. Briggs, MCh(Orth),

FRCS(Ed), FRCS, Consultant

Orthopaedic Surgeon

The Royal National

Orthopaedic Hospital, Brockley

Hill, Stanmore HA7 4LP, UK.

A. E. Goodship, BVSc,

MRCVS, PhD, Professor of

Orthopaedic Sciences at the

University College London and

the Royal Veterinary College

Royal Veterinary College,

Hawkhead Lane, North Mimms,

Hertfordshire AL9 7TA, UK.

Correspondence should be sent

to Ms C. J. Pendegrass; e-mail:

c.pendegrass@ucl.ac.uk

(C)2005 British Editorial Society

of Bone and

Joint Surgery

doi:10.1302/0301-620X.87B6.

$15363 \$ 2.00$

$J$ Bone Joint Surg [Br]

2005;87-B:873-8.

Received 30 January 2004;

Accepted after revision

26 August 2004

\title{
Extensor mechanism reconstruction after proximal tibial replacement
}

\begin{abstract}
We developed an in vivo model of the attachment of a patellar tendon to a metal implant to simulate the reconstruction of an extensor mechanism after replacement of the proximal tibia. In 24 ewes, the patellar tendon was attached to a hydroxyapatite (HA)-coated titanium prosthesis. In 12, the interface was augmented with autograft containing cancellous bone and marrow. In the remaining ewes, the interface was not grafted.

Kinematic gait analysis showed nearly normal function of the joint by 12 weeks. Forceplate assessment showed a significant increase in functional weight-bearing in the grafted animals $(p=0.043)$. The tendon-implant interface showed that without graft, encapsulation of fibrous tissue occurred. With autograft, a developing tendon-bone-HA-implant interface was observed at six weeks and by 12 weeks a layered tendon-fibrocartilage-bone interface was seen which was similar to a direct-type enthesis.
\end{abstract}

With stable mechanical fixation, an appropriate bioactive surface and biological augmentation the development of a functional tendon-implant interface can be achieved.

Endoprosthetic replacement of the proximal tibia in tumour surgery is a successful alternative to amputation, arthrodesis or reconstruction by allograft..$^{1-5}$ The proximal tibia has certain anatomical limitations to its reconstruction. In particular there is a need for an effective method for reattachment of the patellar tendon. ${ }^{2}$ Altered biomechanics because of failure of the extensor mechanism can result in patella alta, atrophy of the quadriceps and altered gait with an extensor lag. ${ }^{2,3}$ Contemporary methods for reattachment of the patellar tendon produce an impaired functional outcome. ${ }^{4,5}$ Assessment of function in clinical practice is commonly based on the scoring system of the Musculoskeletal Tumour Society, which assigns numerical values for the six categories of pain, function, emotional acceptance, supports, walking and gait. ${ }^{6}$

The morphology of the tendon-implant interface is poorly understood in relation to the observed clinical and functional outcome because of limited retrieval data. We have developed an in vivo model to simulate reattachment of the tendon to a massive prosthesis. We have used two objective measures to assess outcome combined with histological evaluation. We have tested the hypothesis that by using our implant with autogenous cancellous bone and marrow graft, a tendon-implant interface will develop which is similar in function and morphology to a natural enthesis.

\section{Materials and Methods}

Implant. We designed a metal implant consisting of a titanium-alloy (Ti6A14V) base plate to simulate the extramedullary surface of a proximal tibial replacement. The implant was coated with a 10 to $100 \mu \mathrm{m}$ thick layer of hydroxyapatite (HA) which was plasma sprayed (Plasma Biotal, Tideswell, UK). The mechanical stability of the tendon clamp was provided by nine interlocking spikes which were $4 \mathrm{~mm}$ long and $1 \mathrm{~mm}$ in diameter, of which six were pressfitted into the base plate and three into an $\mathrm{H}$ shaped lid (Fig. 1).

Operative technique. We used 26 Friesland ewes weighing 55 to $90 \mathrm{~kg}$ (mean $71.5 \mathrm{~kg}$ ) in accordance with the Home Office Animals (Scientific Procedures) Act 1986. Anaesthesia was induced by $2.5 \mathrm{mg}$ of Hypnovel (midazolam; Roche Products Limited, Welwyn Garden City, UK) and $2 \mathrm{mg} / \mathrm{kg}$ of Ketaset (ketamine hydrochloride; Fort Dodge Animal Health Ltd, Southampton, UK) given intravenously. Anaesthesia was maintained with $3 \%$ halothane (Merial Animal Health Ltd, Harlow, UK). A midline incision was made over the right stifle (knee) joint and the patellar tendon was detached from the tibial tuberosity by sharp dissection. The tibial tuberosity was osteoto- 


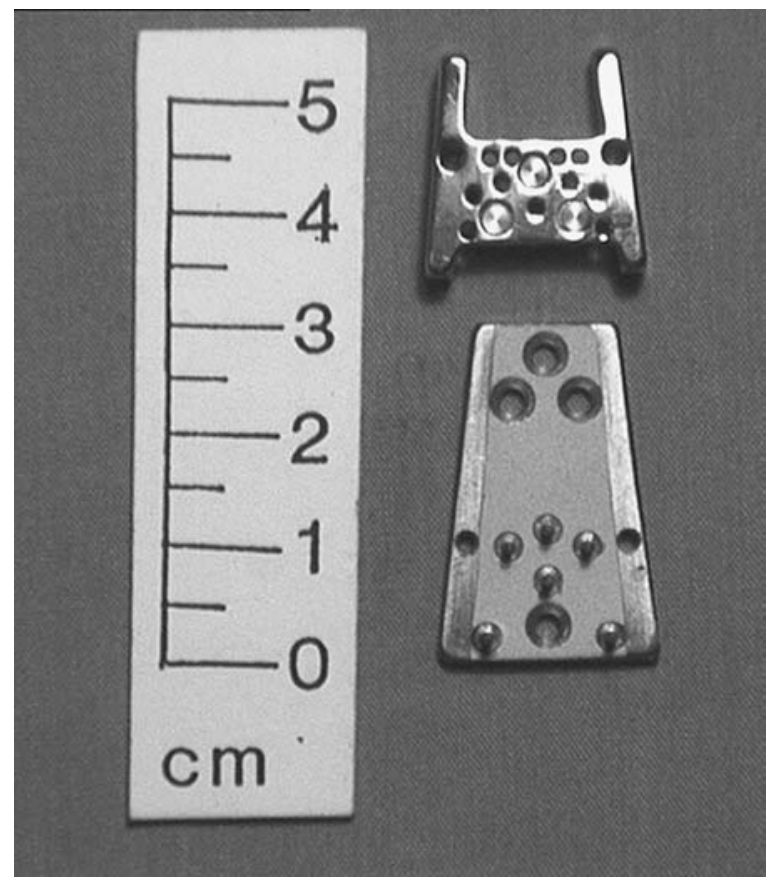

Fig. 1

Photograph of the implant showing the HA-coated base plate (internal surface with six upwardly protruding press-fit spikes) and the $\mathrm{H}$-shaped clamp lid (external surface with back of three pressfit spikes visible) with 1-mm drill holes.

mised and the HA-coated base plate was screwed to the resulting bone bed. The lid of the clamp was assembled onto the base plate thereby transfixing the tendon between the spikes (Fig. 2). The animals were randomly allocated to one of two experimental groups. In the first group of 12 ewes (autograft group), the tendon-HA interface was augmented with fresh morsellised autogenous cancellous bone and marrow graft harvested intra-operatively from the ipsilateral iliac crest (slurry wet weight $\sim 1.5 \mathrm{~g}$ ). In the second group, also of 12 ewes (HA group), there was no interface augmentation. In another two animals (negative controls), the same surgical procedure was performed but the tendon was sutured into the surrounding fascia and not clamped into the implant in order to determine the weight-bearing status of animals with a deficient extensor mechanism. The animals received peri-operative doses of $10 \mu \mathrm{g} / \mathrm{kg}$ of intramuscular Vetergesic analgesic (buprenorphine hydrochloride; Alstoe Ltd; Animal Health Ltd, Melton Mowbray, UK), and subcutaneous Excenel RTU (ceftiofur; Pharmacia, Corby, UK) antibiotic in a dosage of $1 \mathrm{mg} / \mathrm{kg}$. Further doses were given at one and five days post-operatively, respectively. The animals were allowed to mobilise freely and were group housed in a large indoor pen in a barn.

Kinematic gait analysis. All the animals underwent preoperative two-dimensional kinematic gait analysis of the right stifle joint using an infrared light-emitting diode camera system (Qualisys ProReflex (Ver.6.42); Qualisys AB, Gothenberg, Sweden). A camera recorded the positional

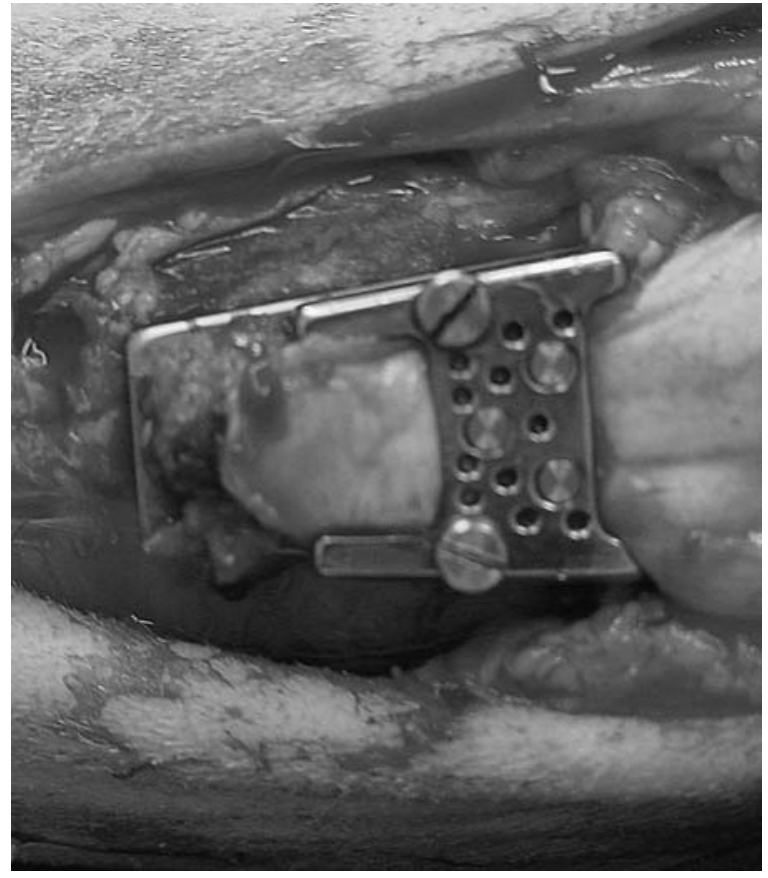

Fig. 2

Photograph of the patellar tendon fixed with the clamp.

change in the sagittal plane of four reflective markers positioned on the greater trochanter, the lateral distal femoral condyle, the lateral proximal tibial condyle and the lateral distal tibia, over a period of ten seconds. Fifteen walks were performed and the data captured by Qualisys QTrac software (version 2.56) were exported as files accessible to Microsoft Excel (Microsoft Corp, Redmond, Washington). A custom-written program was used to calculate the range of movement at the stifle joint. A further angle was derived based on the calculated difference between the pre-operative and post-operative angle of the stifle joint in extension. This angle was designated as a lag angle if negative, or recurvatum if positive. The kinematic data recorded allowed an accurate determination of gait speed during each walk to be made, based on the time taken to cross the field of view of the camera.

Force-plate assessment. The animals underwent forceplate assessment (Kistler Biomechanics Limited, Alton, UK), and the data from 12 walks were collected for each hind limb. Using custom-written software, the mean peak vertical ( $\mathrm{z}$ co-ordinate) component of the ground reaction force (GRF), normalised for the weight of the animal (Fmax/weight), was obtained for both the operated and control hind limb. The mean peak vertical (Fz) GRF of the right hind limb as a percentage of that of the left hind limb was calculated.

Duration of experiment. Six weeks after the operation all the animals underwent force-plate analysis of both hind 


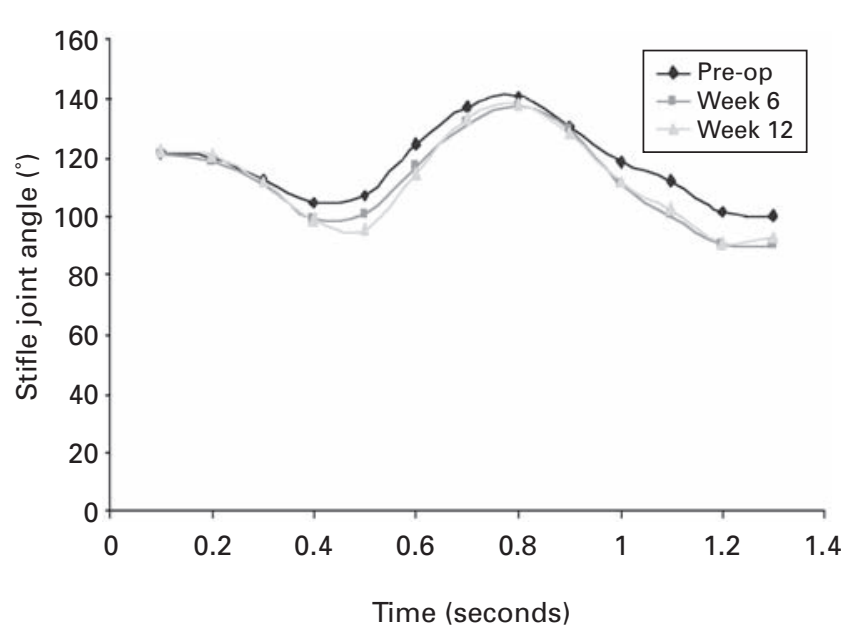

Fig. 3

The range of movement of the joint through the gait cycle for one animal at the three time points.

limbs. Twelve (six from each group) had gait analysis of the right hind limb and were killed. Both proximal tibiae and patellar tendons were harvested. The remaining 12 animals had further force-plate and gait analysis at 12 weeks after operation before being killed.

Histological evaluation. Specimens were fixed in $10 \%$ formalin, dehydrated in ascending alcohol concentrations, defatted in chloroform and embedded in LR White Resin (London Resin Company Limited, London, UK). Sections were cut, ground and polished to a thickness of $100 \mu \mathrm{m}$ and were then stained with toluidine blue and paragon. Histomorphological assessment was carried out using an Olympus BH2 microscope (Olympus Optical Company Ltd, Tokyo, Japan), linked to Zeiss KS300 3.0 image-analysis software (Imaging Associates, Thame, UK).

Statistical analysis. Numeric data were entered using SPSS for Windows version 10.1 (SPSS, Chicago, Illinois). The data were analysed using non-parametric tests. Gait speeds were compared between the pre- and post-operation time points for animals in the HA and autograft groups using the Wilcoxon signed-rank test. The Mann-Whitney U test was used to examine differences between the range of movement, extensor lag, and GRF data between the HA and autograft groups at six and 12 weeks after operation. The Wilcoxon signed-rank test was used to examine differences in Fmax/weight for the operated and control limbs for the two groups. The results were considered to be significant at $\mathrm{p}<0.05$.

\section{Results}

All the animals tolerated the surgery and were mobile within 24 hours of surgery. One developed a superficial wound infection which was treated successfully with oral antibiotics.

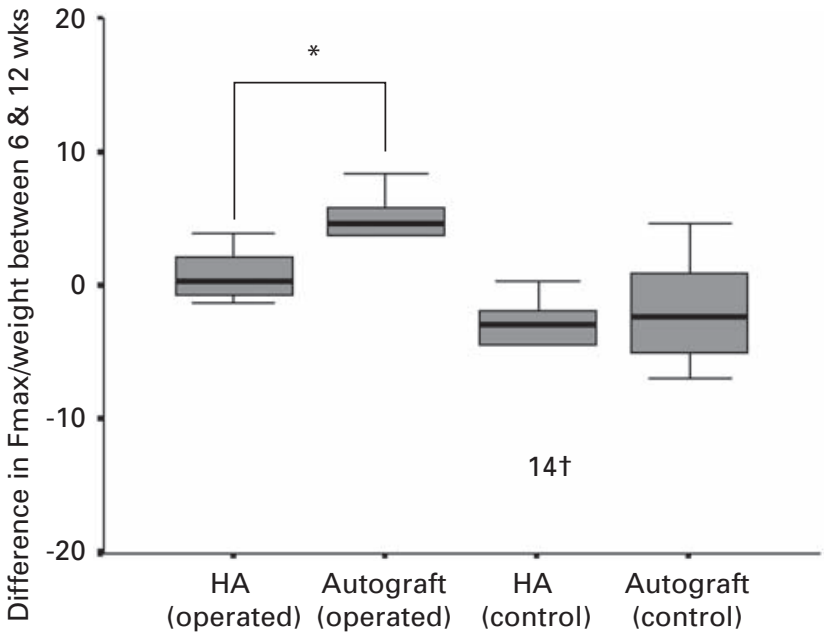

Fig. 4

Box-and-whiskers plot showing the Fmax/weight for the operated and non-operated hind limbs $\left(^{*}\right.$, significant value of $p=0.043 ; \dagger$ outlying data point).

Functional data. The two negative-control animals did not complete the force-plate assessment, being unable to bear weight at both time points. In both the HA and autograft groups, there were no significant differences in the gait speed before and after operation (HA, $\mathrm{p}=0.616$; autograft, $\mathrm{p}=0.448$ (six weeks); HA, $\mathrm{p}=0.580$; autograft $\mathrm{p}=0.148$ (12 weeks)). At six and 12 weeks, the range of movement of the stifle joint was not significantly different from the pre-operative range in both the HA (six weeks, $\mathrm{p}=0.055 ; 12$ weeks, $\mathrm{p}=0.078$ ) and autograft (six weeks, $\mathrm{p}=0.055 ; 12$ weeks, $\mathrm{p}=0.078$ ) groups (Fig. 3 ). At six weeks, the median value of the extensor lag was $-17.21^{\circ}$ (95\% confidence interval (CI) -6.14 to -30.54 ) and $-14.63^{\circ}$ (95\% CI -5.21 to -24.30 ) for the autograft and HA groups, respectively, with no significant differences between the groups $(p=0.631)$. A full recovery of extension was recorded by 12 weeks, with a median $(95 \%$ CI) lag or recurvatum in extension of $-1.02^{\circ}(-17.81$ to 19.75$)$ and $1.25^{\circ}(-13.02$ to 18.48$)$ for the autograft and HA groups, respectively, with no significant differences between the groups $(\mathrm{p}=0.749)$.

At six weeks, the GRF (Fz) for the operated/control limbs expressed as a percentage was 65.70 (95\% CI 58.79 to $72.24)$ and $66.08(95 \%$ CI 56.73 to 73.59$)$ for the autograft and HA groups, respectively $(\mathrm{p}=0.954)$. By 12 weeks this had increased to 90.55 (95\% CI 58.99 to 101.44) and 80.27 (95\% CI 69.44 to 88.50$)$ ( $\mathrm{p}=0.465$ ). The change in functional weight-bearing between six and 12 weeks showed that for the operated limb, there was a significant increase in the Fmax/weight for the autograft group compared with the HA group $(p=0.043)$. By contrast, there was no significant difference in the change in Fmax/weight for the non-operated (control) limb between autograft and HA groups ( $\mathrm{p}=0.345)$ (Fig. 4). 


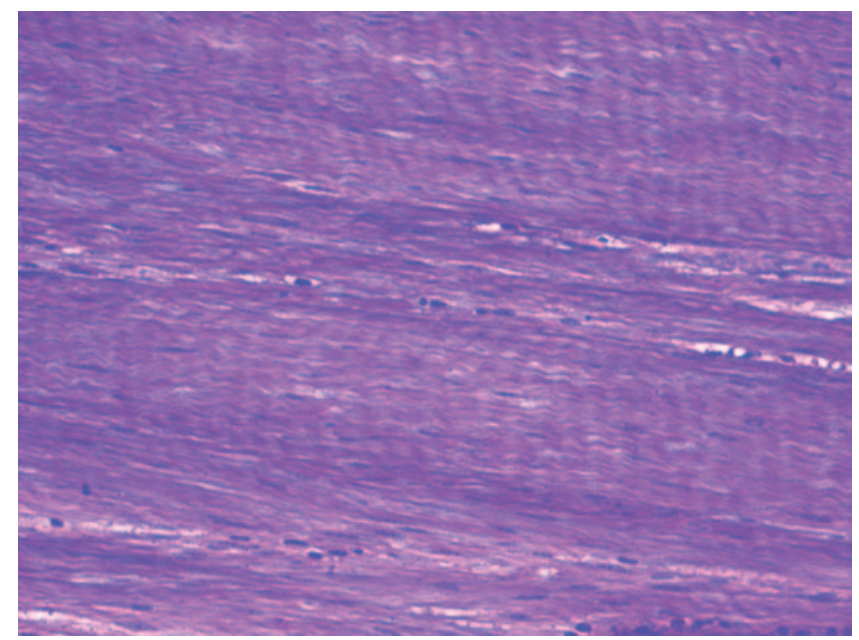

Fig. 5

Photomicrograph of a clamped tendon in the autograft group at 12 weeks. There is dense collagenous connective tissue showing fibres with a crimped pattern (toluidine blue and paragon, x66).

Gross morphology. In all cases, a continuation of the patellar tendon was observed running into the implant clamp with no observed tendon pull-out.

Histological findings. The non-operated insertion of the normal patellar tendon was observed to be a direct-type enthesis, ${ }^{7}$ with the tendon inserting into the bone through intermediate tissue of unmineralised and mineralised fibrocartilage. In the operated limb in both groups, normal tendon consisting of parallel, crimped collagen fibres was observed to run into the tendon clamp. At six weeks, this clamped tendon showed an alteration in morphology in both the HA and autograft groups. The tissue displaying inflammatory and degenerative changes was interspersed with regions of more normal morphology. At 12 weeks, the tissue had organised and matured such that the clamped tissue resembled normal tendon, with parallel, crimped, collagen fibres, interspersed with elongated fibroblast nuclei (Fig. 5).

At both time points, the tendon-HA interface in the HA group showed encapsulation of fibrous tissue. At six weeks, this was a disorganised interface consisting of a mixed inflammatory infiltrate and a population of plump fibroblasts surrounded by randomly-aligned collagen fibres. By 12 weeks, the fibroblasts were oval in shape, and collagen fibres were observed to be aligned in the direction of tensile load. No formation of bone was observed within the clamped region in the HA group.

In the autograft group at six weeks, the bone graft was observed to be undergoing active remodelling and was seen to be intimately associated with the HA layer. Collagen fibres from the tendon were seen to penetrate the bone directly, resulting in a tendon-bone-HA-implant interface (Fig. 6). By 12 weeks, a layered tendon-fibrocartilage-bone attachment was observed both where bone was retained at

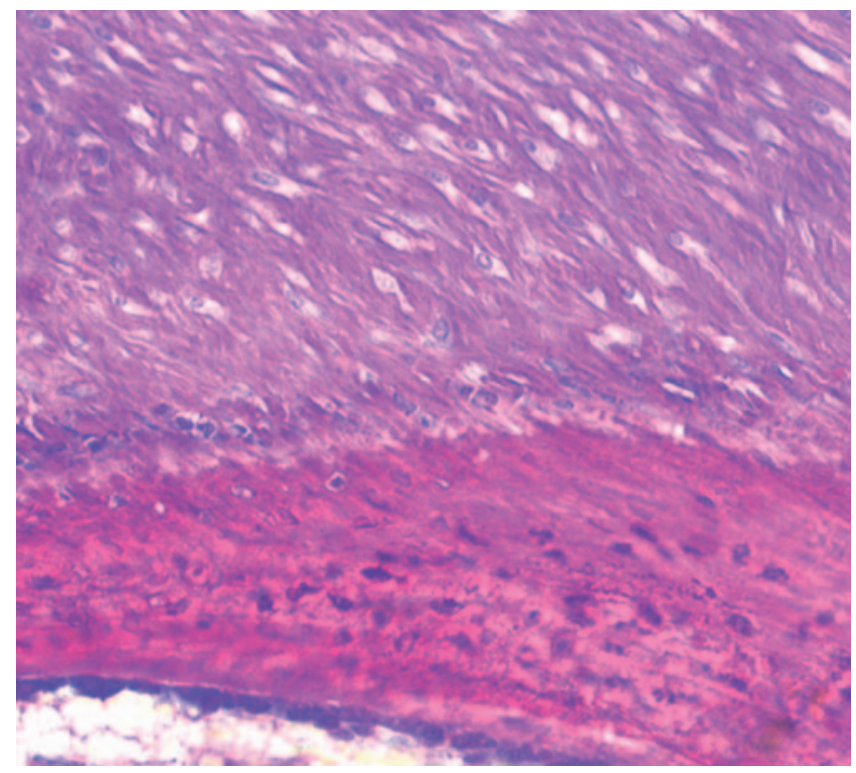

Fig. 6

Photomicrograph of the tendon-bone-HA interface in the autograft group at six weeks. Penetrating collagen fibres are seen spanning between the tendon and bone (toluidine blue and paragon, x100).

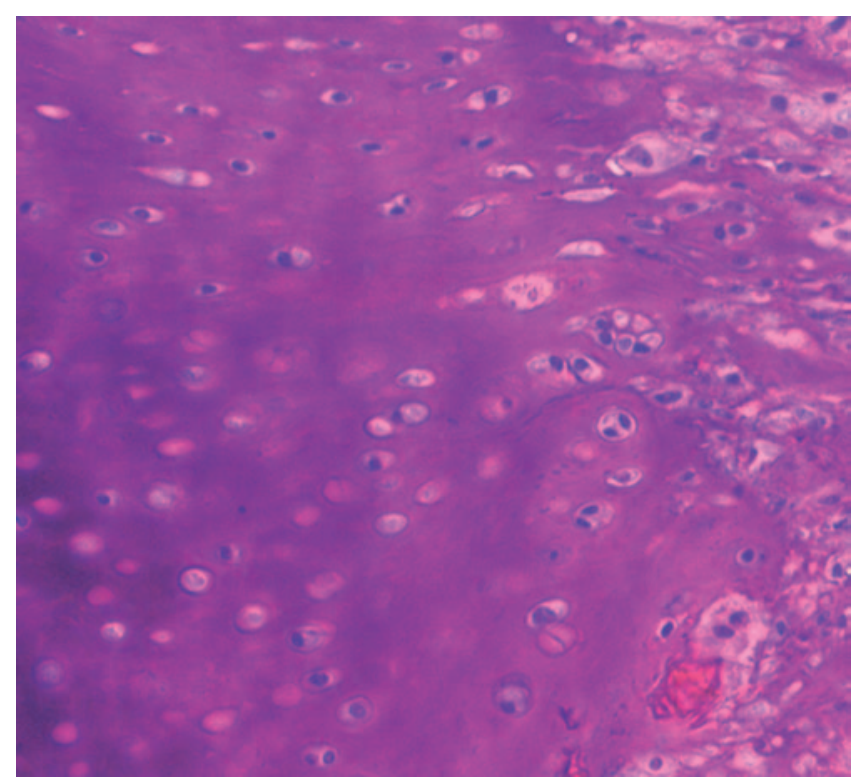

Fig. 7

Photomicrograph of the tendon-bone interface in the autograft group at 12 weeks. A fibrocartilaginous intermediate zone was observed with rounded chondrocyte-like cells in lacunae (toluidine blue and paragon, $\mathrm{x} 100)$.

the HA surface, and where it was observed away from the HA base plate (Fig. 7). Where morsellised bone graft had become dislodged from the surface of the implant, a similar tendon-bone interface was observed. In regions of the autograft group where the bone graft had become dissociated from the HA surface, the tendon-HA surface consisted 
of a fibrous encapsulation similar to that seen in the HA group. Dense collagenous tissue consisting of parallelorientated fibres, interspersed with elongated fibroblast nuclei was noted to stream through the drill holes and the unclamped regions of the tendon as a result of the open $\mathrm{H}$ shaped lid into the clamp.

\section{Discussion}

We report direct re-attachment of the patellar tendon to a HA-coated metal implant and have shown nearly normal kinematic function of the joint. The interlocking spikes provided mechanical stability allowing immediate weightbearing, with no evidence of failure by pull-out. Devices to clamp soft tissues have been used in some prostheses. ${ }^{2}$ In massive prostheses, non-absorbable sutures and slings have been used as the primary attachment mechanism. ${ }^{1,4,5,8,9}$ Spiked devices for mechanical fixation have been studied experimentally and used clinically. ${ }^{10-12}$ It has been speculated that interlocking-spike mechanisms may produce less tissue damage because of perforation of the tendon while under compression. ${ }^{12}$ Rempel and Abrahamsson ${ }^{13}$ studied local ischaemia on tendon explants in vitro and found that hypoxia significantly inhibited the synthesis of collagen but had no effect on cell proliferation, or the synthesis of proteoglycan or non-collagenous protein. The clamp lid was designed to allow access to the clamped tendon from overlying vascular tissue. We cannot predict the in vivo compression forces with the clamp but we did not observe tissue necrosis.

At 12 weeks, in both groups nearly-normal extensor function and range of movement were observed equivalent to those of the normal stifle joint. We feel that this is a reflection of the identical mechanical method of re-attachment and not of the biological processes. With longer term studies, differences may become apparent. We have demonstrated that lack of tendon re-attachment results in the animals being unable to bear weight.

Kinematic gait analysis has been used in clinical studies and in vivo experimental models. ${ }^{14,15}$ Reflective skin markers overlying skeletal prominences are used to define body segments. This technique has been criticised for inconsistencies in defining surface anatomy and problems with skin displacement. In our study markers were applied after assessment of the surface anatomy. Displacement of the skin was considered to be negligible based on radiographs of the limbs, to which metal-backed markers had been applied, in different degrees of flexion and extension. There are limitations of single-joint two-dimensional kinematic analysis but this method was judged to be more objective than the subjective scales of function used in other similar studies. ${ }^{16}$ Other studies have shown similar functional weight-bearing over equivalent periods of time, ${ }^{12,17}$ but these have not included a kinematic outcome. Force-plate systems have been used to assess the function of the limb, clinically and experimentally. ${ }^{18-20}$ The forces transduced through the patellar tendon are related to the vertical GRF
(Fz) in vivo. ${ }^{21}$ Force-plate data can be considered to be a surrogate for in vivo tensile loading through the developing enthesis. The weight-bearing response of individual animals meant that differences between the HA and autograft groups did not reach significance. By considering the change in Fmax/weight, we normalised the data to eliminate differences in initial weight-bearing. The increase in Fmax/weight through the operated limb was significantly greater in the autograft group compared with the nonaugmented HA group $(\mathrm{p}<0.05)$, which we speculate may be attributable to the biological augmentation.

When graft was not used encapsulation of fibrous tissue occurred which is in agreement with other studies of direct soft-tissue attachment to metal. ${ }^{12,22}$ In the autograft group, new bone formed in apposition to the HA similar to that observed in other studies. ${ }^{23-26}$ At six weeks, the presence of perforating fibres of collagen and new woven bone was similar to that seen in tendon-bone tunnel studies, ${ }^{27-30}$ where attachment occurred by anchoring collagen fibres. ${ }^{30}$ With graft, the trabeculae of the cancellous bone and marrow provided an osteoconductive scaffold. The graft contributed to a pool of pluripotential cells ${ }^{31}$ which have been shown to induce osteogenesis. ${ }^{32,33}$ HA has been shown to induce differentiation of stem cells along an osteoblast lineage. ${ }^{34}$ It provides a bioactive surface which supports mineralisation, induces collagen synthesis and produces stable fixation of the implant. ${ }^{23-25}$

The difficulty of attaching the soft tissues to massive prostheses limits the success of the procedure. Our study is valid as a generic model for tendon-implant attachment. We appreciate that this is a quadruped model in which the in vivo forces may differ from those in a biped model. Patellar tendon forces of $800 \mathrm{~N}$ for walking have been recorded in a goat ${ }^{21}$ which was tolerated by our clamp. Further experimental work is required before our techniques can be incorporated into prosthetic design. Our work suggests that the goal of attaching tendons to prostheses may be feasible and we feel that these results are sufficiently encouraging to warrant ongoing studies.

This study was supported by Stanmore Implants Worldwide Ltd and the Royal National Orthopaedic Hospital NHS Trust Culyer Fund.

Although none of the authors has received or will receive benefits for personal or professional use from a commercial party related directly or indirectly to the subject of this article, benefits have been or will be received but will be directed solely to a research fund, foundation, educational institution, or other nonprofit organisation with which one or more of the authors are associated.

\section{References}

1. Eckardt JJ, Matthews JG, Eilber FR. Endoprosthetic reconstruction after bone tumor resections of the proximal tibia. Orthop Clin North Am 1991;22:149-60.

2. Cannon SR. Massive prostheses for malignant bone tumours of the limbs. J Bone Joint Surg [Br] 1997;79-B:497-506.

3. Jeon DG, Kawai A, Boland P, Healey JH. Algorithm for the surgical treatment of malignant lesions of the proximal tibia. Clin Orthop 1999;358:15-26.

4. Malawer MM, McHale KA. Limb-sparing surgery for high-grade malignant tumors of the proximal tibia: surgical technique and a method of extensor mechanisms reconstruction. Clin Orthop 1989;239:231-48.

5. Ozaki T, Kunisada T, Kawai A, Takahara Y, Inoue H. Insertion of the patella tendon after prosthetic replacement of the proximal tibia. Acta Orthop Scand 1999;70: $527-9$ 
6. Enneking W, Dunham W, Gebhardt M, Malawar M, Pritchard D. A system for the functional evaluation of reconstructive procedures after surgical treatment of tumours of the musculoskeletal system. Clin Orthop 1993;286:241-6.

7. Benjamin M, Kumai T, Milz S, et al. The skeletal attachment of tendons: tendon entheses. Comp Biochem Physiol Mol Integr Physiol 2002;133:931-45.

8. Jensen JS. Resection arthroplasty of the proximal tibia. Acta Orthop Scand1983;54:126-30.

9. Gosheger G, Hillmann A, Lindner N, et al. Soft tissue reconstruction of megaprostheses using a trevira tube. Clin Orthop 2001;393:264-71.

10. Gottsauner-Wolf F, Egger EL, Markel MD, Schultz FM, Chao EY. Fixation of canine tendons to metal. Acta Orthop Scand 1994;65:179-84.

11. Meriam C, Beynnon BD, Fleming BC, et al. The effect of screw insertion torque on tendons fixed with spiked washers. Trans ORS 1995;20:614.

12. Gottsauner-Wolf F, Egger EL, Schultz FM, Sim FH, Chao EY. Tendons attached to prostheses by tendon-bone block fixation: an experimental study in dogs. J Orthop Res 1994;12:814-21.

13. Rempel D, Abrahamsson So. The effects of reduced oxygen tension on cell proliferation and matrix synthesis in synovium and tendon explants from the rabbit carpal tunnel: an experimental study in vitro. J Orthop Res 2001;19:143-8.

14. Chen PQ, Cheng CK, Shang HC, Wu JJ. Gait analysis after total knee replacement for degenerative arthritis. J Formos Med Assoc 1991;90:160-6.

15. Laassel EM, Loslever P, Angue JC. Patterns of relations between lower limb angle excursions during normal gait. J Biomed Eng 1992;14:313-20.

16. Gottsauner-Wolf F, Egger EL, Giurea A, et al. Biologic attachment of an allograft bone and tendon transplant to a titanium prosthesis. Clin Orthop 1999;358:101-10.

17. Inoue N, Ikeda K, Young DR, et al. Tendon fixation to porous metallic implant using autogenous bone graft augmentation. Trans ORS 1996;21:352.

18. Otis JC, Lane JM, Kroll MA. Energy cost during gait in osteosarcoma patients after resection and knee replacement and after above-the-knee amputation. J Bone Joint Surg $[A m]$ 1985;67-A:606-11.

19. Ghosh P, read R, Armstrong S, et al. The effects of intraarticular administration of hyaluronan in a model of early osteoarthritis in sheep. I. Gait analysis and radiological and morphological studies. Semin Arthritis Rheum 1993;22:18-30.

20. Muir P, Johnson KA, Cooley AJ, Manley PA. Force-plate analysis of gait before and after surgical excision of calcified lesions of the supraspinatus tendon in two dogs. Vet Rec 1996;139:137-9.
21. Korvick DL, Cummings JF, Grood ES, et al. The use of an implantable force transducer to measure patellar tendon forces in goats. J Biomech 1996;29:557-61.

22. LaBerge M, Bobyn JD, Rivard CH, Drouin G, Duval P. Study of soft tissue ingrowth into canine porous coated femoral implants designed for osteosarcomas management. J Biomed Mater Res 1990;24:959-71.

23. Ducheyne P, Hench LL, Kagan A 2nd, et al. Effect of hydroxyapatite impregnation on skeletal bonding of porous coated implants. J Biomed Mater Res 1980;14:225-37.

24. Geesink RG. Hydroxyapatite-coated total hip prostheses: two-year clinical and roentgenographic results of 100 cases. Clin Orthop 1990;261:39-58.

25. Soballe K, Hansen ES, B-Rasmussen H, Jorgensen PH, Bunger C. Tissue ingrowth into titanium and hydroxyapatite-coated implants during stable and unstable mechanical conditions. J Orthop Res 1992;10:285-99.

26. Kienapfel H, Sprey C, Wilke A, Griss P. Implant fixation by bone ingrowth. J Arthroplasty 1999:14:355-68.

27. Jones JR, Smibert JG, McCullough CJ, Price AB, Hutton WC. Tendon implantation into bone: an experimental study. J Hand Surg [Br] 1987;12-B:306-12.

28. Rodeo SA, Arnoczky SP, Torzilli PA, Hidaka C, Warren RF. Tendon-healing in a bone tunnel: a biomechanical and histological study in the dog. J Bone Joint Surg [Am] 1993;75-A:1795-803

29. Shaieb MD, Singer DI, Grimes J, Namiki H. Evaluation of tendon-to-bone reattachment: a rabbit model. Am J Orthop 2000;29:537-42.

30. Oguma H, Murakami G, Takahashi-Iwanaga H, Aoki M, Ishii S. Early anchoring collagen fibers at the bone-tendon interface are conducted by woven bone formation: light microscope and scanning electron microscope observation using a canine model. J Orthop Res 2001;19:873-80.

31. Caplan Al. Mesenchymal stem cells. J Orthop Res 1991;9:641-50

32. Goshima J, Goldberg VM, Caplan Al. The osteogenic potential of cultureexpanded rat marrow mesenchymal cells assayed in vivo in calcium phosphate ceramic blocks. Clin Orthop 1991;262:298-311.

33. Oreffo RO, Driessens FC, Planell JA, Triffitt JT. Growth and differentiation of human bone marrow osteoprogenitors on novel calcium phosphate cements. Biomaterials 1998;19:1845-54.

34. Rust PA, Blunn GW, Cannon SR, Briggs TW. Use of a novel bioreactor to grow a bone block using human mesenchymal stem cells on a porous hydroxyapatite scaffold. Trans ORS 2003;28:74. 